Journal of Computer Science 7 (7): 967-972, 2011

ISSN 1549-3636

(C) 2011 Science Publications

\title{
Evaluation of Artificial Immune System with Artificial Neural Network for Predicting Bombay Stock Exchange Trends
}

\author{
${ }^{1}$ M. Gunasekaran and ${ }^{2}$ K.S. Ramaswami \\ ${ }^{1}$ Department of Computer Applications, \\ Park College of Engineering and Technology, Coimbatore, India \\ ${ }^{2}$ Department of Mathematics, Coimbatore Institute of Technology, Coimbatore, India
}

\begin{abstract}
Problem statement: The purpose of this study is to develop an artificial immune system for recognizing stock market trends and predict upward and downward directions of stock market. This study compared two prediction models, an Artificial Immune System (AIS) and Artificial Neural Network (ANN) for predicting the future index value, trend of Indian stock market and discovers the best prediction model. Approach: AIS is an efficient system for predicting trend due to its high capability of learning and retaining information in memory. Our proposed system was tested using SENSEX (Sensitive Index) data from Bombay Stock Exchange (BSE) of India. Results: Performance of models have been evaluated on the basis of the simulation results done on MATLAB. Experiments have been performed for both methods on well-known technical indicators and compared their results with SENSEX data. Conclusion: Artificial Immune System is more efficient than Artificial Neural Network.
\end{abstract}

Key words: Artificial immune system, artificial neural network, technical indicators, bombay stock exchange, stock market

\section{INTRODUCTION}

Recent research activities on the Artificial Immune System (AIS) have established that immune system have powerful prediction and pattern recognition capabilities. In recent years, dealing with uncertainty is the big issue. We implement Artificial Immune System (AIS) is a new kind of natural computation method to deal this uncertainty efficiently for predicting the stock trend.

Artificial Immune System (AIS) is a computational intelligence model to formulate adaptive systems capable of performing a wide range of tasks in various engineering applications, such as abnormality detection, pattern classification and recognition. AIS are motivated by biological immune system, which have the immune system's characteristics of learning and memory.

A neural network has the capability to process the input variables in parallel and can manage large amounts of data in rapid manner (Hsieh, 2010). The greatest strength of neural network is its skill to discover patterns easily. Artificial Neural Networks (ANN) has been widely accepted to deal with stock market prediction (Chang et al., 2009; Majee and Roy, 2010).
Technical indicators are used to determine the behavior of investors and their impact on the future price movement of the stock from past movements. A well performing stock portfolio, that allows investors to diversify away unsystematic risk and enhance the quality of investment by selling and buying the stock (Vazakidis and Adamopoulos, 2009). The main data of our studies are the price histories of stock, with time and volume information. Down and up trends of the price on the stock market depends on supply and demand of stocks.

The SENSEX is a weighted average of 30 shares market value of the Bombay Stock Exchange (India). The SENSEX was introduced by Bombay Stock Exchange (BSE) in 1986. The BSE SENSEX is considered as a benchmark in this experiment. The main objective of the study is to develop predictive model for finding the next day's close value of SENSEX.

The remainder of this study is organized as follows: Initially different prediction models are described. After that Artificial Immune System and Artificial Neural Network are tested and compared with BSE Sensex in order to predict the trend of Indian market. Then the experimental results and numerous discussion issues are presented. Finally the conclusions are summarized relatively.

Corresponding Author: M. Gunasekaran, Department of Computer Applications, Park College of Engineering and Technology, Coimbatore, India 


\section{MATERIALS AND METHODS}

Number of researchers has proposed to analyze and predict stock market activity for the last two decades. Linear methods dominated prediction for the past several years. Linear methods are simple to recognize and interpret and they are also comparatively easy to create and deploy. Linear models also have serious problems on the other side which are unable to identify non-linear relationships in stock market data.

Artificial Neural Network (ANN) model: Artificial Neural Network (ANN) methodology allows us to develop nonlinear systems receiving large quantities of inputs that development based on only instances of input-output relations (Vazakidis and Adamopoulos, 2009). A major application field of ANNs is forecasting. ANN is especially best fit for discovering accurate solutions in an environment characterized by nonlinear, irrelevant, complex, partial or noisy data (Eletter et al., 2010). However, several limitations happened even if they were recognized with multi dimensional nonlinear models.

The multi layer feed forward neural network model with back propagation algorithm for training is employed for predicting stock market is shown in Fig. 1. A Neural network essentially has three layers which are the input layer, the output layer and the hidden layer in between. Neural network is made up of interconnected neurons and each neuron has the relationship with neighboring neurons. The relationship between the neurons is measured by weight.

The input layer $\mathrm{x}$ of neurons acquires the data directly from the stock exchange. After computation has been performed by the hidden layer $\mathrm{y}$, resultant outputs are transferred to output layer $\mathrm{z}$. Output of node in hidden layer is derived from inputs, weight of connections and a nonlinear function called as activation function (Solaimani, 2009).

Actual output of node in hidden layer $y$ is defined as:

$$
\mathrm{AO}_{\mathrm{y}}=\mathrm{f}\left(\operatorname{sum}_{\mathrm{x}}\right)
$$

Where:

$$
\operatorname{sum}_{\mathrm{y}}=\sum_{\mathrm{x}=1}^{\mathrm{n}} \mathrm{w}_{\mathrm{xy}} \mathrm{AO}_{\mathrm{x}}
$$

Where:

$\mathrm{w}_{\mathrm{xy}}=$ The weight of the connections between input node $\mathrm{x}$ and hidden node $\mathrm{y}$

$\mathrm{AO}_{\mathrm{x}}=$ The actual output of node $\mathrm{x}$ and $\mathrm{f}$ is the activation function

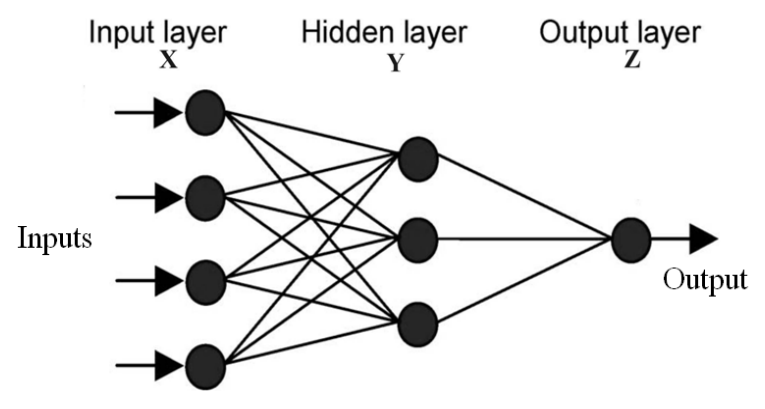

Fig. 1: Artificial neural network

Back propagation algorithm adjusts the weights of connections slightly. Output layer has only one neuron. We can compare the actual output $\mathrm{AO}$ and the predicted output $\mathrm{PO}$ for the output layer $\mathrm{z}$ and variation $\mathrm{V}$ between these values is measured as:

$\mathrm{V}=\frac{1}{2} \sum_{\mathrm{z}=1}^{\mathrm{n}}\left(\mathrm{PO}_{\mathrm{z}}-\mathrm{AO}_{\mathrm{z}}\right)^{2}$

Back propagation algorithm decides to increase or decrease weights $\mathrm{w}_{\mathrm{xy}}$ for minimizing the variation:

$\mathrm{w}_{\mathrm{xy}}=\mathrm{w}_{\mathrm{xy}} \pm \Delta \mathrm{w}_{\mathrm{xy}}$

where, $\mathrm{w}_{\mathrm{xy}}$ is the weight of the link between the node $\mathrm{x}$ and node $\mathrm{y}$.

On neural network, number of suitable neurons is presented in the input and hidden layers can modify the prediction performance (Alsmadi and Omar, 2010; Dastorani et al., 2010).

Artificial immune system model: In recent years, Artificial Immune System (AIS) is introduced among the different categories of prediction methods. Artificial Immunology concept was proposed by Professor Forrest, University of New Mexico in 1997 (Wang et al., 2009). Artificial Immune System (AIS) is a new computational intelligence method inspired by biology immune system (Deng and Gao, 2009). A human immune system consists of B-cells that recognize antigens which entering from external environment. B-cells are a type of immune cell, depending on protein molecules called antibody (Golzari et al., 2011). A B-cell identifies the antigen when its antibodies appear into contact with an antigen of complementary shape (Do et al., 2009). In a discrete immune network, cells and molecules can enlarge or reduce in number and may also change their 
behavior to develop their similarity. The discrete immune networks adjust many elements and adjust the construction of these elements. This approach is facilitating to solve many problems. It obviously deals the relationship with the external environment (antigens) as the discrete immune networks planned at problem solving.

A pseudo-code for AIS algorithm is given below:

1. Generate an initial antibodies

2. while stopping criteria is not met do

3. Estimate the fitness value of each antibody against the antigen

4. Find the better fitness value among antibodies

5. while solution $\neq$ fitness value do

6. Apply mutation for getting exact fitness value for solution

7. end while

8. produce cloned antibodies

9. if solution $=$ fitness value of cloned antibody

10. then produce more cloned antibody and set cloned antibody as antibody

11. end if

12. end while

13. return the best solution found

In Artificial Immune Network, each element corresponds to a B-cell composed of an antibody. Euclidean distance is a distance between each antigen and antibody (or a B cell) is given by Eq. 5:

$$
\mathrm{ED}_{\mathrm{ij}}=\sqrt{\sum_{\mathrm{x}}^{\mathrm{n}}\left(\mathrm{AG}_{\mathrm{ix}}-\mathrm{AB}_{\mathrm{jx}}\right)}
$$

Where:

$$
\begin{aligned}
& \mathrm{AG}_{\mathrm{ix}}=\mathrm{x}^{\text {th }} \text { attribute value of antigen } \mathrm{i} \\
& \mathrm{AB}_{\mathrm{jx}}=\mathrm{x}^{\text {th }} \text { attribute value of antibody } j
\end{aligned}
$$

The probability of selecting an antibody from the population of antibodies $\mathrm{AB}$ according to the population of antigens $A G$ is given as:

$$
\mathrm{p}(\mathrm{j})=\frac{\operatorname{antibody}(\mathrm{j})}{\sum_{\mathrm{j}=1}^{\mathrm{n}} \operatorname{antibody}(\mathrm{j})}
$$

Where:

$\mathrm{j}=$ The series of antibody or affinity

$\mathrm{n}=$ The population of antibodies

This study has developed a general artificial immunity system framework to defense current stock data according to the idea mentioned above and it is illustrated in following Fig. 2. Data refining is very important stage, the Sensing phase filter unnecessary data and decrease data quantity for extracting relevant information from the historical stock data. The Detection phase validates the outcome of sensing phase by utilizing knowledge database (Prado et al., 2010). The Defend phase has higher perception level that analyzes a solution synthetically and provides an exact decision. Future trend can be efficiently predicted in this way. The SENSEX index of current stock market has the rise and fall in price and volume may change the result of the detection. To overcome this problem, AIS system updates the knowledge database and the detectors, so the system will adjust itself to discover effectively the changes of external factors.

A financial application has been developed to predict trends using trading rules that suggests investors when should buy or sell various stocks (Widiputra et al., 2009). Technical analysis investigates patterns and movements in price and volume charts by utilizing inferences hidden in past trading activities. It believes that past history will repeat in future and the relationship between price and volume clearly expresses share market performances (Oskooe, 2010).

Technical analysts use technical indicators, which are mathematical formulas that predict the market trend easily (Oskooe, 2010). Among the various technical indicators, we utilize the Simple Moving Average (SMA) and Exponential Moving Average (EMA) between different moving averages and Relative Strength Index (RSI) for the price analysis. Arms Index and Money Flow Index are used for analyzing volume (Chang et al., 2009; Abbondante, 2010).

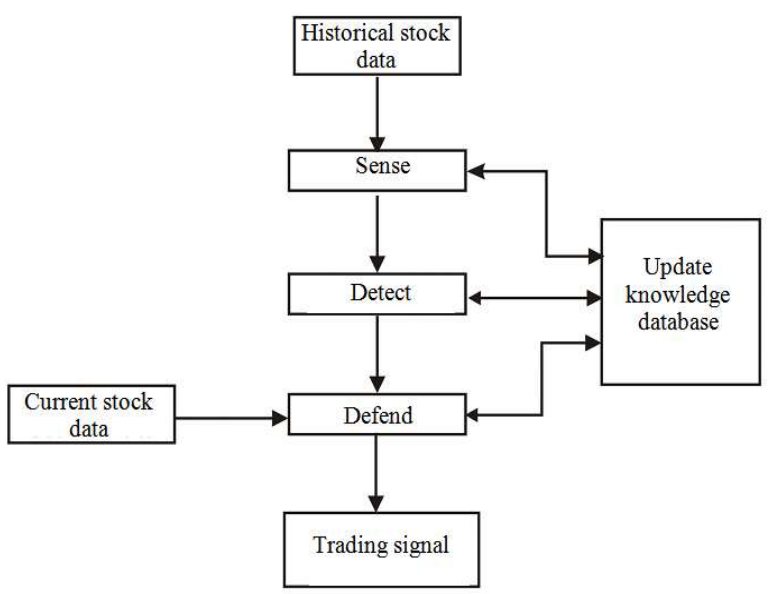

Fig. 2: General framework of artificial immune system 
Table 1: Technical indicators used as input variables

\begin{tabular}{|c|c|c|c|}
\hline S. No & Technical indicators & Description & Formula \\
\hline 1 & Simple Moving Average (SMA) & $\begin{array}{l}\text { Calculates the average price over a specified } \\
\text { moving time period. }\end{array}$ & $(1 / \mathrm{m}) \sum_{\mathrm{i}=\mathrm{t}-\mathrm{m}+1}^{\mathrm{t}} \mathrm{x}_{\mathrm{i}}$ \\
\hline 2 & $\begin{array}{l}\text { Exponential Moving } \\
\text { Averages (EMA) }\end{array}$ & $\begin{array}{l}\text { averages the last } x \text { days closes but } \\
\text { assigns a greater weight to the more } \\
\text { recent prices making it more sensitive } \\
\text { to current price action }\end{array}$ & $\begin{array}{l}\text { EMA }=(\mathrm{CP} \text { current-CP previous })^{*} 2 /(n+1) \\
\quad+\mathrm{CP} \text { previous } \\
\text { Where } \mathrm{CP}-\text { Closing Price }\end{array}$ \\
\hline 3 & Money Flow Index & $\begin{array}{l}\text { Measures the strength of money } \\
\text { flowing into and out of a stock. } \\
\text { It also takes both price and } \\
\text { volume into account. }\end{array}$ & $\begin{array}{l}\text { Money Flow Ratio }=\frac{\text { Positive Money Flow }}{\text { Negative Money Flow }} \\
\text { Where } \\
\text { Money flow }=\text { Avg. Price* Day's Volume } \\
\text { Avg. Price }=\frac{\text { Day's High }+ \text { Day's Low }+ \text { Close }}{3}\end{array}$ \\
\hline 4 & Arms Index & Measures relative volume flows & $\begin{array}{l}\text { Arms Index }=\frac{(\mathrm{AI} / \mathrm{DI})}{(\mathrm{AV} / \mathrm{DV})} \\
\mathrm{AI}=\text { No. of Advancing issues } \\
\mathrm{AV}=\text { Advancing Volume } \\
\mathrm{DI}=\text { No. of Declining issues } \\
\mathrm{DV}=\text { Declining Volume } \\
\text { If } \mathrm{AI}>1.0, \text { Market is down trend } \\
\mathrm{AI}<1.0, \text { Market is up trend }\end{array}$ \\
\hline 5 & $\begin{array}{l}\text { Relative Strength } \\
\text { Index (RSI) }\end{array}$ & $\begin{array}{l}\text { RSI measures the velocity of price } \\
\text { movements and determine the } \\
\text { overbought and oversold condition }\end{array}$ & $\begin{array}{l}\text { RSI=100-[100/ }(1+\mathrm{RS})] \\
\text { where: } \\
\mathrm{RS}=(\text { Avg. of } \mathrm{n} \text {-day up closes }) / \\
\text { (Avg. of } \mathrm{n} \text {-day down closes) } \\
\mathrm{n}=\text { days }(9-15 \text { days) }\end{array}$ \\
\hline
\end{tabular}

We first show how parameters are used to configure the system. The input variables used in this study are based on well-known technical indicators. Both immune network and artificial network use these technical indicators for predicting the stock market trend. We have considered 5 important technical indicators with brief description and formula, as shown in Table 1.

To evaluate the performance of both models for calculating the following statistical metrics, namely Root Mean Squared Error (RMSE), Mean Absolute Error (MAE) and Mean Absolute Percentage Error (MAPE) of the trained forecasting model for the test data (Singh and Ahmad, 2011; Assis et al., 2010).

Root Mean Squared Error (RMSE) is described as follows:

$\operatorname{RMSE}=\sqrt{\frac{1}{\mathrm{n}} \sum_{\mathrm{i}=1}^{\mathrm{n}}\left(\mathrm{A}_{\mathrm{i}}-\mathrm{P}_{\mathrm{i}}\right)^{2}} \times 100$

Mean Absolute Error (MAE) is given as:

$$
\mathrm{MAE}=\frac{1}{\mathrm{n}} \sum_{\mathrm{i}=1}^{\mathrm{n}}\left[\mathrm{A}_{\mathrm{i}}-\mathrm{P}_{\mathrm{i}}\right]
$$

Similarly Mean Absolute Percentage Error (MAPE) is defined as:

$$
\text { MAPE }=\frac{1}{n} \sum_{i=1}^{n}\left[\frac{A_{i}-P_{i}}{A_{i}}\right]
$$

Where:

$A_{i}=$ Actual value of index on day $i$

$\mathrm{P}_{\mathrm{i}}=$ Predicted value on day $\mathrm{i}$ of forecasting models

If the above RMSE is very less significant, the prediction accuracy of the system is very close to $100 \%$.

\section{RESULTS}

The prediction models have been successively implemented and tested on MATLAB based Graphical User Interface. The system was tested on India BSE SENSEX Index using historical data from 20092010. We have used separate data sets for training and testing. Both neural network and immune network will be trained using the data from 2nd January 2009 to 31 st July 2009 . The testing period is selected to be from 3rd August 2009 to 30th July 2010. We have considered the historical data as a source of information on the closing prices of BSE SENSEX index. Our objective is to compare the predicted results and values of above mentioned methodologies with current trends of BSE SENSEX index. 


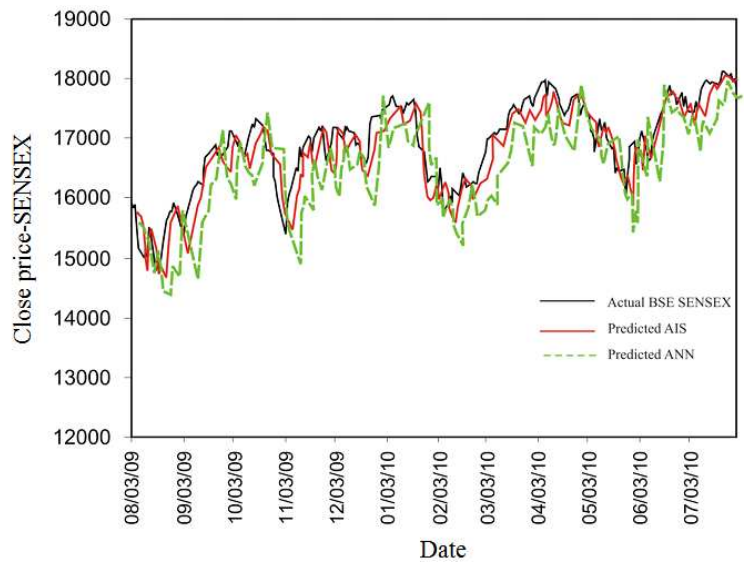

Fig. 3: Actual and projected value of BSE SENSE X generated by the AIS and ANN

Table 2: Evaluation of AIS and ANN using test data

\begin{tabular}{llcr}
\multicolumn{4}{l}{ Table 2: Evaluation of AIS and ANN using test data } \\
\hline & ERRORS & & \\
Methods & RMSE & MAE & MAPE \\
\hline AIS & 103.106 & 75.315 & 0.831 \\
ANN & 178.136 & 163.452 & 1.832 \\
\hline
\end{tabular}

Comparisons and results of both AIS and ANN models were evaluated by estimating the error between the current price of closing and the predicted closing price. Figure 3 shows the predicted results of AIS and ANN models and performance of predicted models were compared with actual BSE SENSEX index.

The above graph demonstrates the predicted values of two prediction models during the period 2009 -2010. The actual values for the period are also illustrated. We evaluated the forecast accuracy measures for this period. The prediction performance is evaluated by considering the variation between the predicted value and actual value. Table 2 obviously shows the results have been obtained by two different models, such as AIS and ANN for predicting BSE SENSEX index.

\section{DISCUSSION}

In this study, we have proposed the Artificial Immune System for predicting the stock market movement. Our new AIS prediction model is compared with another ANN prediction model and benchmark index SENSEX. We clearly identified that the predicted AIS data is very close to actual SENSEX data than predicted ANN data from the above Fig. 3. The statistical measures of prediction errorRMSE, MAE and MAPE of AIS were significantly lower than those obtained with ANN as indicted in the above Table 2. From above empirical results, it is very evident that the AIS model gives better results on the problem of stock market forecasting. As a result, the Artificial Immune System can be used to predict the stock market trend efficiently.

\section{CONCLUSION}

Numerous soft computing approaches have been applied effectively in predicting the movement of stock trend and produced better performance. In this study, we have proposed an immune based computational strategy for predicting the stock trend which includes sensing, detecting and defending. The experimental studies have been conducted on the Bombay Stock Exchange (BSE SENSEX Index, Period: August 2009-July 2010) datasets. Most of the research papers proposed the ANN model for predicting non-linear data such as stock market. Recently, AIS has the ability to predict nonlinear data very well. This study is evaluated and compared the performance of ANN and AIS models. The AIS model has the lowest value of RMSE, MAE and MAPE. Our experimental results propose that the AIS model can provide better predictions than the standard ANN model. We will improve optimal way to fuse the various intelligent systems using a hybrid approach in future work. We will consider different methodologies to overcome the drawbacks of a specific intelligent system. We will also develop multi-layer presentations of AIS for handling the abnormal characteristics of stock market.

\section{REFERENCES}

Abbondante, P., 2010. Trading volume and stock indices: A test of technical analysis. Am. J. Econ. Bus. Admin., 2: 287-292. DOI: 10.3844/ajebasp.2010.287.292

Alsmadi, M.K. and K.B. Omar, 2010. Fish recognition based on robust features extraction from size and shape measurements using neural network. J. Comput. Sci., 6: 1088-1094. DOI: $10.3844 /$ jcssp.2010.1088.1094

Assis, K., A. Amran, Y. Remali and H. Affendy, 2010. A comparison of univariate time series methods for forecasting cocoa bean prices. Trends Agric. Econ., 3: 207-215. DOI: $10.3923 /$ tae.2010.207.215

Chang, P.C., C.Y. Fan and C.H. Liu, 2009. Integrating a piecewise linear representation method and a neural network model for stock trading points prediction. IEEE Trans. Syst., Man Cybernetics-Part C: Appli. Rev., 39: 80-92. DOI: $10.1109 /$ TSMCC.2008.2007255 
Dastorani, M.T., A. Talebi and M. Dastorani, 2010. Using neural networks to predict runoff from ungauged catchments. Asian J. Applied Sci., 3: 399-410. DOI: 10.3923/ajaps.2010.399.410

Deng, L. and D.Y. Gao, 2009. Research on immune based adaptive intrusion detection system model. Proceedings of the International Conference on Networks Security, Wireless communications and Trusted Computing, Apr. 25-26, IEEE, Hubei, China, pp: 488-481. DOI: 10.1109/NSWCTC.2009.87

Do, T.D., S.C. Hui anmd A.C.M. Fong, 2009. Associative classification with artificial immune system. IEEE Trans. Evolut. Comput., 13: 217228. DOI: 2008-06-10 17:02:03.0

Eletter, S.F., S.G. Yaseen and G.A. Elrefae, 2010. Neuro-based artificial intelligence model for loan decisions. Am. J. Econ. Bus. Admin., 2: 27-34. DOI: 10.3844/ajebasp.2010.27.34

Golzari, S., S. Doraisamy, M.N. Sulaiman and N.I. Udzir, 2011. An efficient and effective immune based classifier. J. Comput. Sci., 7: 148-153. DOI: $10.3844 /$ jcssp.2011.148.153

Hsieh, K.L., 2010. Employing artificial neural networks into achieving parameter optimization of multi-response problem with different importance degree consideration. Inform. Technol. J., 9: 918-926. DOI: 10.3923/itj.2010.918.926

Majee, N.C. and A.B. Roy, 2010. Asymptotic behavior of an artificial neural network defined on multipartite directed graph. OnLine J. Biol. Sci., 10: 44-49. DOI: 10.3844/ojbsci.2010.44.49
Oskooe, S.A.P., 2010. Emerging stock market performance and economic growth. Am. J. Applied Sci., 7: 265-269. DOI: 10.3844/ajassp.2010.265.269

Prado, R.P., N. Garcia-Galá, S. Exposito and J. Yuste, 2010. Knowledge acquisition in fuzzyrule-based systems with particle-swarm optimization. IEEE Trans. Fuzzy Syst., 18: 10831097. DOI: 10.1109/TFUZZ.2010.2062525

Singh, V.K. and N. Ahmad, 2011. Forecasting performance of constant elasticity of variance model: Empirical evidence from India. Int. J. Applied Econ. Finan., 5: 87-96. DOI: 10.3923/ijaef.2011.87.96

Solaimani, K., 2009. A study of rainfall forecasting models based on artificial neural network. Asian J. Applied Sci., 2: 486-498. DOI:10.3923/ajaps.2009.486.498

Vazakidis, A. and A. Adamopoulos, 2009. Stock market development and economic growth. Am. J. Applied Sci., 6: 1932-1940. DOI: 10.3844/ajassp.2009.1932.1940

Wang, W., S. Gao and Z. Tang, 2009. Improved pattern recognition with complex artificial immune system. J. Soft. Comp., 13: 1209-1217. DOI: $10.1007 / \mathrm{s} 00500-009-0418-0$

Widiputra, H., R. Pears, A. Serguieva and N. Kasabov, 2009. Dynamic interaction networks in modelling and predicting the behaviour of multiple interactive stock markets. Intell. Syst. Acc. Fin. Mange., 16: 189-205. www.interscience.wiley.com, DOI: 10.1002/isaf.300 